\title{
Особенности структурных напряжений в нитевидных нанокристаллах InGaN/GaN
}

\author{
(С) И.П. Сошников ${ }^{1,2,3}$, К.П. Котляр ${ }^{1,4}$, Р.Р. Резник ${ }^{5}$, В.О. Гридчин ${ }^{1,4}$, В.В. Лендяшова ${ }^{1,2}$, \\ А.В. Вершинин ${ }^{1}$, В.В. Лысак ${ }^{5}$, Д.А. Кириленко ${ }^{2}$, Н.А. Берт ${ }^{2}$, Г.Э. Цырлин ${ }^{1,2,3}$ \\ ${ }^{1}$ Санкт-Петербургский Академический университет им. Ж.И. Алфёрова Российской академии наук, \\ 194021 Санкт-Петербург, Россия \\ ${ }^{2}$ Физико-технический институт им. А.Ф. Иоффе Российской академии наук, \\ 194021 Санкт-Петербург, Россия \\ ${ }^{3}$ Институт аналитического приборостроения Российской академии наук, \\ 198095 Санкт-Петербург, Россия \\ ${ }^{4}$ Санкт-Петербургский государственный университет, \\ 199034 Санкт-Петербург, Россия \\ ${ }^{5}$ Университет ИТМО, \\ 197101 Санкт-Петербург, Россия \\ E-mail: ipsosh@beam.ioffe.ru
}

Поступила в Редакцию 12 апреля 2021 г.

В окончательной редакции 19 апреля 2021 г.

Принята к публикации 19 апреля 2021 г.

\begin{abstract}
Представлено экспериментальное исследование, направленное на развитие метода спонтанного синтеза нитевидных нанокристаллов InGaN/GaN радиальной гетероструктуры при молекулярно-пучковой эпитаксии. Методами электронной микроскопии показано, что при содержании In $x=0.4$ и 0.04 в ядре и оболочке и размерах ядра может образоваться клиновидная трещина. На основе модели внутренних структурных напряжений предложена формула, позволяющая оценить критические размеры и состав для образования трещин в нитевидных нанокристаллах. Сопоставление оценок и экспериментальных данных морфологии дает хорошее согласие между собой.
\end{abstract}

Ключевые слова: нитевидные нанокристаллы, молекулярно-пучковая эпитаксия, осевые гетероструктуры, напряженные гетероструктуры, нитрид индия, нитрид галлия.

DOI: $10.21883 /$ FTP.2021.09.51295.25

\section{1. Введение}

Радиальные гетероструктуры (РГС) на основе нитевидных нанокристаллов (ННК) III-N материалов представляют особый интерес в связи с перспективами их приложений в оптоэлектронике, пьезотронике, а также для генерации водорода при фоторазложении воды [1-3]. В отличие от аксиальных гетероструктур на основе HНК III-N материалов формирование радиальной гетероструктуры типа „ядро-оболочка“ подразумевает рост материала на неполярных и полуполярных кристаллографических плоскостях ННК. Такой дизайн гетероструктуры позволяет минимизировать поляризационные эффекты, характерные для аксиальных гетероструктур $[4,5]$. Большое отношение площади поверхности к объему ННК определяет перспективы их применения в областях, где главную роль играют поверхностные эффекты [6]. Также увеличение площади гетероперехода существенно увеличивает фотопоглощение или эмиссию света в сравнении с аксиальными гетероструктурами на основе ННК [7].

Развитие исследований в указанном направлении до последнего времени было ограничено вследствие проблем с синтезом структур. Как правило, синтез РГС ННК проводился по методике, включающей рост „ядра“ и последующее наращивание „оболочки“ [8]. Несмотря на контролируемое формирование такой гетероструктуры, существует проблема синтеза наноструктур с высоким составом по In порядка $30-50 \%[9,10]$, что существенно сужает спектральный диапазон излучения таких структур.

Другим возможным подходом к формированию радиальных гетероструктур является спонтанное формирование InGaN/GaN РГC на основе ННК. В [2,10] было показано, что при синтезе InGaN HНК методом газофазной эпитаксии возможно спонтанное формирование InGaN/GaN радиальной гетероструктуры с составом по In $\sim 30 \%$. Представленная работа направлена на развитие метода спонтанного синтеза НHK $\mathrm{InGaN} / \mathrm{GaN}$ радиальной гетероструктуры при молекулярно-пучковой эпитаксии (МПЭ). Особое внимание уделено особенностям морфологических и структурных свойств таких ННК.

\section{2. Экспериментальные методы}

Синтез InGaN HНК проводился в установке МПЭ Riber Compact 12, оснащенной плазменным источником азота Addon RF-N 600. Методика роста ННК описана в работах $[11,12]$. На первом этапе загруженные в ростовую камеру подложки $\mathrm{Si}(111)$ р-типа проводимо- 
сти нагревались до $950^{\circ} \mathrm{C}$ для удаления слоя естественного оксида. После этого температуру подложки понижали до $660^{\circ} \mathrm{C}$ и инициировали источник плазмы азота. После стабилизации температуры подложки одновременно открывались заслонки источников галлия и индия. Потоки галлия и индия при синтезе InGaNнаноструктур были равны между собой и эквивалентны давлению $1 \cdot 10^{-7}$ Торр. Поток активированного плазмой азота соответствовал давлению $1 \cdot 10^{-6}$ Торр, расход азота $F_{\mathrm{N} 2}=0.4 \mathrm{~cm}^{3} /$ мин, мощность плазменного разряда составила 400 Вт. Время синтеза составляло 21 ч. По окончании ростового процесса образцы охлаждались до комнатной температуры и выгружались из установки МПЭ для изучения морфологических и структурных свойств.

Исследование морфологии и кристаллической структуры ННК проводилось методами растровой и просвечивающей электронной микроскопии (РЭМ и ПЭМ) на микроскопах Supra 25 (C.Zeiss) и JEM-2100F (Jeol), оснащенном приставкой для энергодисперсионного элементного анализа Quantax EDX XFlash 6 (Bruker).

\section{3. Результаты и обсуждение}

На рис. 1 представлены типичные РЭМ-изображения InGaN HНК, выращенных при температуре подложки $T_{s}=660^{\circ} \mathrm{C}$. Высота массива ННК составила 2.2 мкм, со средней плотностью массива $7 \cdot 10^{9} \mathrm{~cm}^{-2}$. Характерные латеральные размеры ННК вдоль оси роста, совпадающей с кристаллографической осью [0001] в нитридах, составляют от 120 до 40 нм у вершины. В сечении ННК имеют форму неправильных шестигранников (рис. $1, b)$.
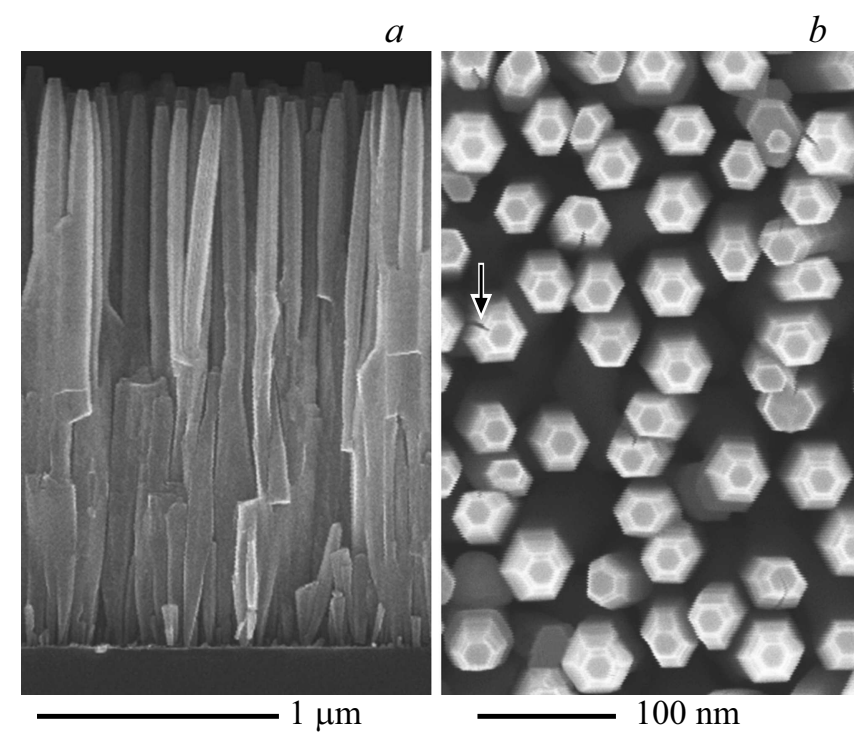

Рис. 1. Типичные РЭМ-изображения в геометрии поперечное сечение $(a)$ и вид сверху $(b)$ массива InGaN нитевидных нанокристаллов, синтезированных на $\mathrm{Si}$ подложке. Стрелкой указана трещина в ННК.

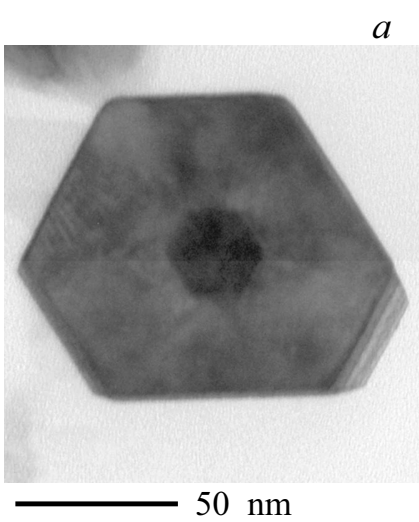

$a$

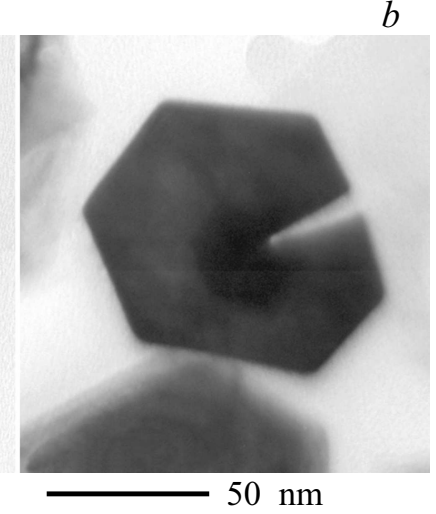

Рис. 2. Типичные ПЭМ-изображения вершин InGaN HНК без трещины $(a)$ и с трещиной $(b)$.

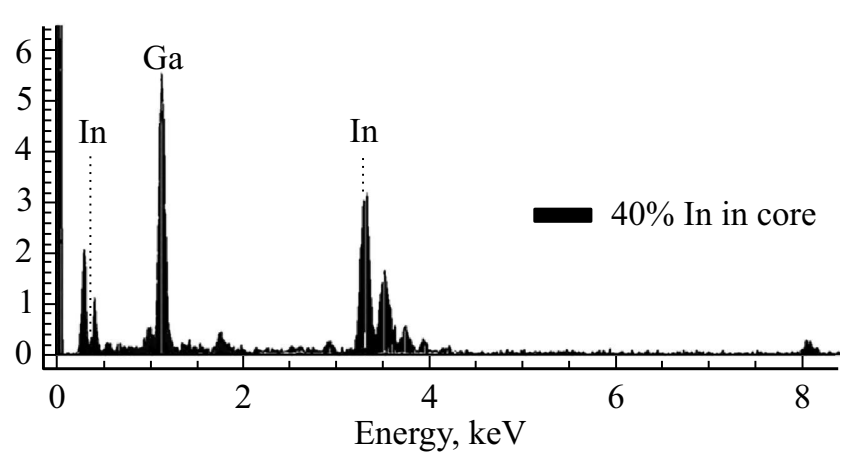

Рис. 3. Энергодисперсионный спектр микроанализа от „ядра“ ННК.

Морфология ряда ННК содержит „клиновидные трещины“, что свидетельствует о наличии структурных напряжений внутри ННК. В большинстве случаев трещины начинаются в области центра ННК и раскрываются в направлении к грани, существенно реже - к ребру. Угол раствора клина составляет от 7 до $25^{\circ}$, а доля нитевидных нанокристаллов с трещинами достигает $15 \%$ от общего числа ННК.

На рис. 2, $a, b$ представлены ПЭМ-изображения сечения InGaN HНК с трещиной и без. По данным ПЭМ, в результате синтеза формируются ННК с огранкой по плоскостям $(11 \overline{2} 0)$ в виде неправильного шестигранника (рис. 2,a). В центральной области ННК (ядро центральная область ННК вдоль оси роста) наблюдается контраст изображений, связанный с повышенным содержанием In. Содержание In во внешней области и ядре ННК, по данным ПЭМ энергодисперсионного анализа, составляет порядка $x=0.03$ и 0.4 соответственно (рис. 3). Характерные размеры ядра составляют порядка от 20 до 50 нм в поперечном сечении, оно также огранено плоскостями (112̄0).

Формирование структуры типа „ядро InGaN-оболочка GaN“ происходит спонтанно в теле ННК. Теоретическое обоснование механизма формирования такой структуры выходит за рамки настоящего исследования и будет 

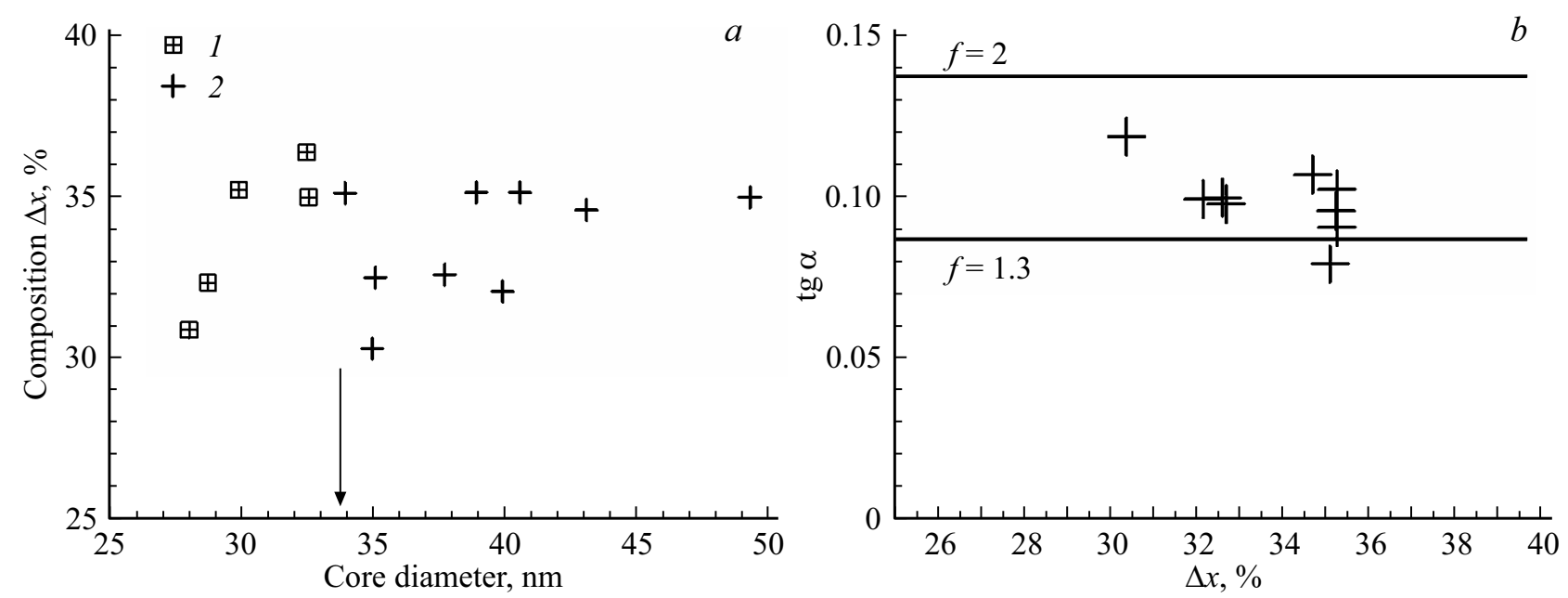

Рис. 4. $a$ - зависимость геометрических параметров и состава структуры „ядро $\mathrm{InGaN}$ - оболочка GaN“: $1-\mathrm{HHK}$ без трещин, 2 - с трещиной. Стрелкой отмечен критический размер ядра ННК. $b$ - зависимость угла раскрытия трещины от контраста состава „ядро-оболочка“. Горизонтальные прямые соответствуют оценкам тангенса угла раскрытия при значениях параметра релаксации напряжений $f=1,3$ и 2.

изложено в отдельной работе. На рис. 4, а показана диаграмма распределения диаметр „ядра“-контраст состава „ядро InGaN-оболочка $\mathrm{GaN}^{\text {“ }}$ по In. Видно, что при величине диаметра ядра > 34 нм наблюдается образование клиновидных трещин. В то же время при размерах ядра $<34$ нм трещин не наблюдается.

Образование трещин является пластической деформацией разрыва в „оболочке“ структуры. Предельный радиус ядра ННК для образования пластической деформации может быть определен в рамках классической модели напряжений „стержень в оболочке“ для упругих и пластических деформаций [13-22]:

$$
R \approx \frac{a_{c}^{2}}{2\left(a_{c}-a_{s}\right)(1+v)}
$$

где $a_{c}$ и $a_{s}$ - параметры решетки ядра и оболочки $\left(a_{c}=x_{c} \cdot a_{\mathrm{InN}}+\left(1-x_{c}\right) \cdot a_{\mathrm{GaN}} \quad\right.$ и $\quad a_{s}=x_{s} \cdot a_{\mathrm{InN}}$ $+\left(1-x_{s}\right) \cdot a_{\mathrm{GaN}}, a_{\mathrm{InN}}=0.355, a_{\mathrm{GaN}}=0.319 \mathrm{HM}[20] ; x_{c}$ и $x_{s}$ - содержание индия в ядре и оболочке структуры; $v=C_{12} /\left(C_{11}+C_{12}\right)$ - параметр пуассоновского сжатия (в случае InN и $\mathrm{GaN} v \approx 0.3[23,24])$. Оценка характерных размеров для пластической деформации в структуре „стержень в оболочке“ дает величину $35 \pm 3$ нм при значениях состава $x_{c} \approx 0.37$ и $x_{s} \approx 0.03$. Сопоставление экспериментальных результатов и теоретической оценки (рис. 4, a) показывает хорошее согласие между собой.

Характерные размеры трещины можно оценить по формуле

$$
\operatorname{tg} \alpha \simeq \frac{2 f\left(a_{c}-a_{s}\right)}{a_{c}}
$$

где $\operatorname{tg} \alpha$ - тангенс угла раствора трещины, $a_{c}$ и $a_{s}-$ параметры решетки ядра и оболочки, $f$ - параметр релаксации напряжений. В $[23,24]$ показано, что величина параметра $f$ может изменяться в пределах от $f \sim(1+v) /(1-v)$ до $f \sim(1+v)$, где $v$ - параметр пуассоновского сжатия.

Сопоставление полученной экспериментальной зависимости тангенса угла раскрытия трещины от структурных напряжений $\left(u \sim \Delta x=x_{c}-x_{s}\right)$ с теоретической оценкой приведено на рис. 4, $b$. Видно, что полученные экспериментальные данные укладываются в области между прямых, соответствующих верхней и нижней границам параметра релаксации напряжений $f$. Отклоняющаяся точка соответствует результату выхода трещины на ребро и должна оцениваться с параметрами для образования трещины в направлении $\langle 1 \overline{1} 00\rangle$.

\section{4. Заключение}

Таким образом, в работе продемонстрировано обра-

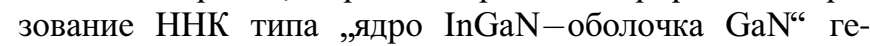
тероструктуры, которая является самоорганизующейся радиальной гетероструктурой и может иметь широкое применение в полупроводниковой оптоэлектронике. На основе модели внутренних структурных напряжений предложена формула, позволяющая оценить критические размеры и состав для образования трещин в ННК. Сопоставление оценок и экспериментальных данных морфологии дает хорошее согласие между собой.

\section{Финансирование работы}

Работа проводилась при поддержке РФФИ (проекты 18-07-01364 и 19-32-90156) и Министерства науки и высшего образования в части государственного задания № 0791-2020-0003. Исследования методами просвечивающей электронной микроскопии выполнялись с использованием оборудования Федерального объединенного исследовательского центра „Материаловедение 
и характеристика в передовых технологиях“ (Физикотехнический институт им. А.Ф. Иоффе РАН, СанктПетербург, Россия).

\section{Конфликт интересов}

Авторы заявляют, что у них нет конфликта интересов.

\section{Список литературы}

[1] S. Li, A. Waag. J. Appl. Phys., 111, 071101 (2012).

[2] Q. Luo, R. Yuan, Y.-L. Hu, D. Wang. Appl. Surf. Sci., 537, 147930 (2021).

[3] A. Zhang, G. Zheng, C.M. Lieber. Nanowires Building Blocks for Nanoscience and Nanotechnology (Springer NanoScience and Technology, 2016).

[4] S.R. Routray, T.R. Lenka. Micro-Nano Lett., 12 (12), 924 (2017).

[5] M. Monavarian, A. Rashidi, D. Feezell. Phys. Status Solidi A, 216, 1800628 (2019).

[6] X. Chen, Cell K.Y. Wong, C.A. Yuan, G. Zhang. Sensors and Actuators B: Chemical, 177, 178, (2013).

[7] Y.-L. Tsai, K.-Y. Lai, M.-J. Lee, Y.-K. Liao, B.S. Ooi, H.-C. Kuo, J.-H. He. Progr. Quant. Electron., 49, 1 (2016).

[8] V.G. Dubrovskii. Nucleation Theory and Growth of Nanostructures (Springer Verlag, Berlin- Heidelberg, 2014).

[9] E. Roche, Y. André, G. Avit, C. Bougerol, D. Castelluci, F. Réveret, E. Gil, F. Médard, J. Leymarie, T. Jean, V.G. Dubrovskii, A. Trassoudaine. Nanotechnology, 29, 465602 (2018)

[10] Q.Y. Soundararajah, R.F. Webster, I.J. Griffiths, S.V. Novikov, C.T. Foxon, D. Cherns. Nanotechnology, 29, 405706 (2018).

[11] V.O. Gridchin, K.P. Kotlyar, R.R. Reznik, D.S. Shevchuk, D.A. Kirilenko, N.A. Bert, I.P. Soshnikov, G.E. Cirlin. J. Phys.: Conf. Ser., 1482, 01201 (2020).

[12] R.R. Reznik, V.O. Gridchin, K.P. Kotlyar, N.V. Kryzhanovskaya, S.V. Morozov, G.E. Cirlin. Semiconductors, 54 (9), 884 (2020).

[13] С.П. Тимошенко. Сопротивление материалов (М., Наука, 1965) т. 2, гл 6.

[14] M.V. Nazarenko, N.V. Sibirev, Kar Wei Ng, Fan Ren, Wai Son Ko, V.G. Dubrovskii, Connie Chang-Hasnain. J. Appl. Phys., 113, 104311 (2013).

[15] М.Ю. Гуткин, И.А. Овидько. Дефекты и механизмы прочности в наноструктурных и некристаллических материалах (СПб., Янус, 2000).

[16] И.А. Овидько, А.Г. Шейнерман. Наномеханика квантовых точек и проволок (СПб., Янус, 2004) гл. 2 и 5.

[17] F. Glas. Phys. Rev. B, 90, 125406 (2014).

[18] J.W. Matthews, A.E. Blakeslee. J. Cryst. Growth, 27, 118 (1974).

[19] G. Kastner. Phys. Status Solidi A, 195 (2), 367 (2003).

[20] E. Bellet-Amalric, C. Adelmann, E. Sarigiannidou, J.L. Rouvière, G. Feuillet, E. Monroy, B. Daudin. J. Appl. Phys., 95, 1127 (2004).

[21] M. De la Mata, C. Magén, P. Caroff, J. Arbiol. Nano Letters, 14 (11), 6614 (2014).
[22] O. Madelung, U. Rössler, M. Schulz. New Data and Updates for IV-IV, III-V, II-VI and I-VII Compounds, their Mixed Crystals and Diluted Magnetic Semiconductors, LandoltBörnstein - Group III Condensed Matter (Springer Verlag, Berlin-Heidelberg, 2011) v. 44D, p. 517.

[23] J.W. Cahn. Acta Met., 9 (9), 795 (1961).

[24] Springer Handbook of Crystal Growth, ed. by G. Dhanaraj, K. Byrappa, V. Prasad, M. Dudley (Springer Verlag, BerlinHeidelberg, 2010).

Редактор Г.А. Оганесян

\section{Specifics of the stress in InGaN/GaN nanowires}

I.P. Soshnikov ${ }^{1,2,3}$, K.P. Kotlyar ${ }^{1,4}$, R.R. Reznik ${ }^{5}$, V.O. Gridchin ${ }^{1,4}$, V.V. Lendyashova ${ }^{1,2}$, A.V. Vershinin ${ }^{1}$, V.V. Lysak ${ }^{2}$, D.A. Kirilenko ${ }^{2}$, N.A. Bert ${ }^{2}$, G.E. Cirlin ${ }^{1,3,5}$

${ }^{1}$ Alferov University, 194021 St. Petersburg, Russia

${ }^{2}$ loffe Institute,

194021 St. Petersburg, Russia

${ }^{3}$ Institute for Analytical Instrumentation

of the Russian Academy of Sciences,

190103 St. Petersburg, Russia

${ }^{4}$ St Petersburg State University,

199034 St. Petersburg, Russia

5 ITMO University,

197101 St. Petersburg, Russia

Abstract The spontaneous synthesis of $\mathrm{InGaN} / \mathrm{GaN}$ nanowires of core-shell heterostructure using molecular beam epitaxy is investigated in the work. It is shown by electron microscopy that a wedge-shaped crack can form at In content $x=0.4$ and 0.04 in the core and shell correspondent. Based on the model of internal structural stresses, a formula is proposed for estimation of the critical size and composition for the formation of cracks in NWs. The estimations and experimental data of morphology agree with each other. 